\title{
Matthias Eifler, Die Bibliothek des Erfurter \\ Petersklosters im späten Mittelalter
}

\section{Morwenna Coquelin}

\section{OpenEdition}

\section{Journals}

Electronic version

URL: http://journals.openedition.org/ifha/9391

DOI: 10.4000/ifha. 9391

ISSN: 2198-8943

\section{Publisher}

IFRA - Institut franco-allemand (sciences historiques et sociales)

\section{Electronic reference}

Morwenna Coquelin, « Matthias Eifler, Die Bibliothek des Erfurter Petersklosters im späten Mittelalter», Revue de I'IFHA [Online], Date of review, Online since 30 July 2018, connection on 24 September 2020. URL : http://journals.openedition.org/ifha/9391 ; DOI : https://doi.org/10.4000/ifha.9391

This text was automatically generated on 24 September 2020

(CIFHA 


\section{Matthias Eifler, Die Bibliothek des Erfurter Petersklosters im späten Mittelalter}

Morwenna Coquelin

\section{REFERENCES}

Matthias Eifler, Die Bibliothek des Erfurter Petersklosters im späten Mittelalter. Buchkultur und Literaturrezeption im Kontext der Bursfleder Klosterreform, Weimar-Köln-Wien: Böhlau (Veröffentlichungen der Historischen Kommission für Thüringen, Kleine Reihe, 51), 2016, 1255 p., $150 €$ 
Tiré d'une thèse soutenue en 2014 à Iéna, l'ouvrage vise à la reconstitution et à l'étude minutieuse de la bibliothèque du couvent bénédictin d'Erfurt dans une période de réforme interne à l'ordre bénédictin, Saint-Pierre d'Erfurt rejoignant la congrégation de Bursfelde mais aussi d'évolution plus générale des formes de piété et des prémices de la Réforme - l'étude va jusqu'en 1525. La bibliothèque de Saint-Pierre forme un observatoire remarquable pour vérifier la thèse de Felix Heinzer (2008) sur les liens entre réforme spirituelle et souci accru de la culture écrite : c'est celle de l'un des plus grands centres bénédictins de l'Allemagne moyenne, et, quoique dispersée, l'une des plus riches et des mieux conservées.

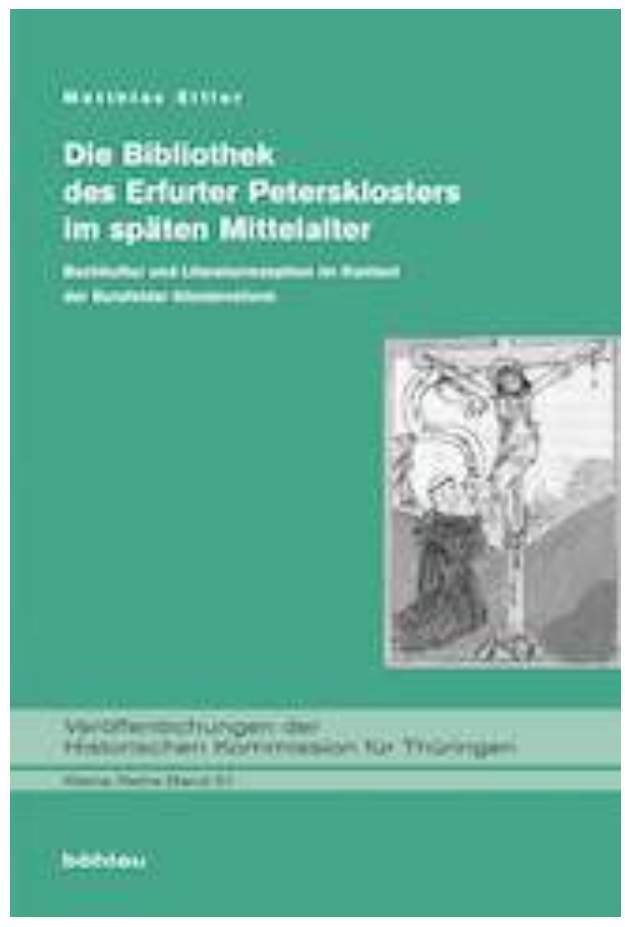

Le premier travail de l'auteur est un considérable effort de recollection de plus de 600 volumes manuscrits ou imprimés (sur les quelque mille que compta la bibliothèque), qui se trouvent dans plus de 90 bibliothèques sur les cinq continents. Ce travail est présenté notamment par de riches annexes (le second volume) : deux catalogues des manuscrits et des imprimés, présentant la localisation des volumes, leur composition, des éléments codicologiques et la bibliographie associée, et l'édition du catalogue de 1783 qui sert de base au travail de localisation. On ne peut que souscrire au vœu de l'auteur de voir renaître cette bibliothèque sous forme virtuelle par la collaboration des différentes institutions concernées. Les nombreuses photographies, dont une large partie en couleur, en donnent un premier aperçu.

Cette reconstitution s'accompagne d'une étude de la construction et du fonctionnement de la bibliothèque, replacée dans l'histoire propre au monastère et à la congrégation de Bursfelde, dont une synthèse est proposée au chapitre II.

La conservation des volumes est l'objet de soins accrus au $\mathrm{XV}^{\mathrm{e}}$ siècle : le monastère dispose de son atelier de reliure, et la collection est organisée par l'établissement de cotes, un catalogage, des marques de propriété sur les pages de garde, des sommaires, tous signes allant dans le sens d'une uniformisation et d'une facilité d'utilisation de la bibliothèque. Cet effort de structuration, dont l'auteur souligne qu'il dépendit largement des moines bibliothécaires, accompagne l'accroissement du nombre de volumes et de leur usage.

Saint-Pierre est aussi un lieu dynamique de production. Par la copie, considérée au sein de la congrégation de Bursfelde comme un travail manuel utile à la méditation du moine, et par l'imprimerie : centre de l'innovation, accueillant la première presse de la congrégation et de la ville en 1475 , le monastère joue un rôle moteur en assurant la production et la diffusion des textes centraux de la réforme hors du couvent. La comparaison avec les autres bibliothèques de la congrégation que l'on peut reconstituer montre à la fois que Saint-Pierre d'Erfurt suit un mouvement plus large de 
valorisation de l'écrit et $y$ prend une place particulièrement importante, qualitativement et quantitativement.

Enfin, l'auteur achève son ouvrage par une longue et très minutieuse étude des volumes conservés à Saint-Pierre et par l'analyse du profil de la bibliothèque (chapitre VIII). La ligne de force, dégagée notamment grâce à la part des différents types d'ouvrages (seulement $12,5 \%$ pour les droits civil ou canon, $4 \%$ pour les arts ou la médecine) ou la hiérarchie des cotes, est celle de la dévotion et de la spiritualité monastique.

L'auteur analyse également la culture de l'écrit de façon plus anthropologique, en s'intéressant aux pratiques de lecture des moines, en particulier individuelle, comme un exercice de méditation organisé par l'abbé ou le bibliothécaire par le prêt d'ouvrages pour l'année. L'image d'une congrégation éloignée de la culture qu'on associe traditionnellement à Bursfelde doit donc être nuancée : les moines y disposent de la culture de base pour accéder à des ouvrages de théologie et de dévotion presque exclusivement en latin, beaucoup sont d'anciens étudiants, la bibliothèque est réorganisée, le monastère est un centre de production d'ouvrages, la méditation et la piété privées sont encouragées. L'entrée dans la congrégation et la réforme sont bien associées à une forte scripturalité ; c'est cependant une scripturalité soigneusement organisée par le monastère, dont les choix diffèrent de ceux des donateurs. Certes, un volume présent n'est pas nécessairement lu. Néanmoins, les choix d'acquisition et de production témoignent d'une culture bien identifiable marquée par la devotio moderna et reflétant les préoccupations spirituelles d'un courant réformateur promouvant une théologie de la piété orientée vers la pratique.

Si l'on peut regretter l'absence de conclusions intermédiaires pour accompagner la lecture, cette présentation érudite constitue aussi un panorama d'une partie du paysage intellectuel à la fin du Moyen Âge, puisque M. Eifler ne se contente pas de lister les volumes mais en présente également le contenu, les auteurs, le contexte et l'influence, dressant de la sorte une utile synthèse dont la consultation est facilitée par un index.

\section{INDEX}

Chronological index: Moyen Âge

Subjects: Histoire de la culture, histoire des mentalités, histoire religieuse

\section{AUTHORS}

\section{MORWENNA COQUELIN}

EHESS, Paris 